\title{
A IDENTIDADE VISUAL DOS ALUNOS DO CAp-UERJ
}

\author{
THE VISUAL IDENTITY OF \\ STUDENTS OF CAp-UERJ
}

UERJ - RJ - BRASIL

Christiane de Faria Pereira Arcuri*

\section{RESUMO}

O Projeto de Extensão O CAp-UERJ e suas impressões visuais amplia as articulações crítico-estéticas acerca da disciplina curricular de Artes Visuais e História da Arte, vinculado ao Departamento de Educação Artística - DEFA. Cadastrado no Departamento de Extensão da Universidade do Estado do Rio de Janeiro - UERJ desde o ano de 2015, o Projeto estuda a identidade visual dos alunos do ensino fundamental ao ensino médio no Instituto de Aplicação / CAp-UERJ a partir do levantamento dos objetos estéticos recorrentes no espaço escolar e relevantes para a formação crítico-cultural. Ao expandir as recorrências estéticas na historiografia da arte e a sintaxe visual nos objetos de uso pessoal (tais como mochilas, tênis, estojos, cadernos etc.) do cotidiano escolar, o Projeto desenvolve a pesquisa visual e a experimentação plástica ao propor a criação de novas padronagens condizentes com a formação identitária e cultural dos alunos no panorama carioca.

Palavras-chave: Cultura visual. Identidade. Contemporaneidade. Ensinos fundamental e médio. Rio de Janeiro.

\section{ABSTRACT}

The outreach project "The CAp-UERJ and its Visual Impressions" expands the critical and aesthetic articulations about the curricular discipline Visual Arts and Art History, linked to the Department of Arts Education / DEFA. It has been registered since 2015 in the Outreach Department (DEPEXT) of Rio de Janeiro State University. The project studies the visual identity of students, from elementary education to high school of Institute of Application/Cap-UERJ, taken into account a survey of aesthetic objects in school environment which are relevant to the critical and cultural education. By expanding the aesthetic recurrences in art historiography and visual syntax using personal items from school routine (backpacks, shoes, cases, notebooks, etc.), the project carries out plastic-visual experimentation when it proposes the creation of new patterns which are related to the identity and cultural education of students in Rio de Janeiro.

Keywords: Visual culture. Identity. Contemporaneity. Elementary education and high school. Rio de Janeiro. 


\section{Introduçáo}

O presente artigo é uma reflexão acerca do Projeto de Extensão $O C A p$-UERJ e suas impressóes visuais, cadastrado no Departamento de Extensão / DEPEXT (no 4896) da Universidade do Estado do Rio de Janeiro - UERJ, no decorrer do seu primeiro ano, em 2015. Vale mencionar que o Projeto está avaliado pelo Departamento de Extensão com conceito excelente e está recadastrado para sua efetivação no ano letivo de 2016.

O CAp-UERJ e suas impressóes visuais é um projeto acerca do estudo da identidade visual dos alunos do ensino fundamental (os dois segmentos) ao ensino médio - o público-alvo - no Instituto de Aplicação / CAp-UERJ. O objetivo principal do Projeto visa ampliar as articulaçóes estéticas acerca da disciplina curricular de Artes Visuais e História da Arte do Departamento de Educação Artística - DEFA e a formação crítica dos alunos frente às demandas visuais e identitárias no espaço escolar.

Sua relevância incide na articulaçáo entre o conhecimento acerca da disciplina de Artes Visuais e História da Arte para todos os segmentos de escolaridade do CAp-UERJ e, consequentemente, para todos os alunos envolvidos, da mesma forma que pode ser estendido para toda a comunidade escolar e comunidade externa interessada. O projeto advém do levantamento dos objetos de uso pessoal (tais como mochilas, tênis, estojos, capas de cadernos e fichários, etc.) usados no cotidiano escolar por esses alunos, a fim de que as tendências e os estilos artísticos recorrentes visualmente nesses objetos configurem náo somente a juventude carioca, mas, inclusive, o gosto e as preferências culturais da juventude brasileira.

A partir do panorama da demanda, do consumo e das preferências dos objetos estéticos dos alunos, torna-se possível contribuir com os estudos sobre a formação critico-artística dos jovens cariocas - e possivelmente dilatados à juventude brasileira. Em outras palavras, veremos em que medida os objetos estéticos usados no cotidiano escolar condizem com o imaginário estético-cultural desses alunos, assim como dos jovens cariocas, em princípio.

Em outras palavras, a pesquisa volta-se para a relação entre as tendências estéticas dos objetos e a historiografia da arte, ou seja, nos atentamos às influências/aparências artísticas nas padronagens estéticas e nas embalagens desses objetos mais consumidos pelos jovens cariocas. Do mesmo modo em que pretendemos averiguar, ainda, se os alunos percebem as especificidades visuais e se têm alguma noçáo e/ ou referência quanto às influências estéticas predominantes nesses objetos mais recorrentes no cotidiano escolar.

Desenvolvemos, ainda, nas aulas semanais de Artes Visuais e História da Arte, tanto no ensino fundamental como no ensino médio, novas padronagens estilísticas, ou seja, os alunos criam suas preferências estéticas a partir das experimentaçóes plástico-visuais e as recorrências pesquisadas na historiografia da arte.

\section{Método}

De início, torna-se relevante mencionar que o Projeto, no ano de 2015, foi desenvolvido nas turmas de $7^{\circ}$ ano do ensino fundamental. Para este ano de 2016, será extensivo às turmas do $5^{\circ}$ ano do ensino fundamental e do $2^{\circ}$ ano do ensino médio. Esses anos de escolaridade foram escolhidos porque além de serem as turmas em que leciona a autora, há idades discrepantes e relevantes para os objetivos e hipóteses levantadas pelo projeto. Pesquisar o consumo e as preferências dos objetos estéticos de idades tão diferentes e de realidade escolares tão distantes parece interessante para os resultados da pesquisa. $\mathrm{O}$ Projeto é desenvolvido no decorrer do ano letivo e de acordo com a periodicidade das aulas semanais de 
Artes Visuais e História da Arte. Os encontros são de 50 minutos para as duas turmas de ensino fundamental e de 100 minutos para as duas turmas de ensino médio.

Como etapas metodológicas, o Projeto se atém ao levantamento visual dos objetos estéticos mais usados pelos alunos no espaço escolar; posteriormente, os objetos são pesquisados através de sua sintaxe visual, quer dizer, são observados a partir da padronagem estética com ênfase nas tendências estilísticas, que podem ser agrupadas em geométricas, figurativas e/ou abstratas. Em seguida, como parte do processo de pesquisa, as tendências estilísticas discriminadas nos objetos são associadas a movimentos e estilos artísticos estudados na História da Arte - disciplina obrigatória curricular para esses alunos.

A etapa pragmática e talvez a mais interessante ocorre quando os alunos criam suas próprias padronagens estéticas. Ou seja, os alunos pesquisam e elaboram novos objetos com os elementos visuais mais condizentes com o seu gosto pessoal - e como não dizer, cultural.

Sendo assim, pode-se mencionar que, predominantemente, a metodologia triangular (BARBOSA, 1984) - da teoria à prática, e vice-versa - é desenvolvida no projeto à medida em que há o processo de identificação dos objetos estéticos, a apreciação crítica das influências artísticas em tais objetos e as novas outras proposiçôes plásticas condizentes com o gosto e a identidade visual (e pessoal) dos alunos - náo necessariamente nesta ordem, é importante destacar.

Com o levantamento dos objetos estéticos mais circulantes no ambiente escolar, o estudo pragmático (as propostas visuais) acerca das questóes estéticas atribuídas à forma plástico-visual de tais objetos, são ativadas: a predominância de tendências geométricas; as alusões cotidianas ao figurativismo; a incidência cromática ligada à temporalidade; a recorrências aos volumes, planos e texturas mais predominantes e ligados ao consumo da juventude carioca

É preciso destacar que um dos objetivos gerais do método proposto pelo projeto tem o estímulo ao pensamento reflexivo e ao fazer crítico como menção predominante à cultura visual da contemporaneidade. Em outras palavras, é a partir do reconhecimento da identidade visual dos alunos do CAp-UERJ que as extensóes plástico-visuais ressonantes na Historiografia da Arte e as tendências artísticas nacionais são propiciadas para que ocorra o processo visual identitário.

\section{Das dimensóes plástico-visuais do objeto estético}

O objeto estético torna-se, deste modo, um objeto artístico, foco de estudo por meio das abordagens metodológicas - e pragmáticas - que avaliam: (a) a percepção da aparência e da organização estético-formal; (b) a recorrência artístico-alegórica; e, (c) suas dimensóes semióticas.

Para tanto, deve-se elencar os aspectos considerados a partir da percepção da aparência visual e da organização estético-formal dos objetos (ARNHEIM, 1980; DONDIS, 2007), que consideram: (a) o processo de comunicação estética dos objetos, isto é, as características formais de estilo e seus atributos adotados, tais como o tratamento cromático adequado; os tipos de materiais funcionais utilizados; as proporçóes; os esquemas pictóricos; a diagramaçáo; etc.; (b) a teoria estética aplicada no processo do design do produto; (c) o valor estético atribuído ao objeto variável cultural e economicamente; (d) 
a estética da informação, isto é, quando o indivíduo (no caso, o aluno) valoriza a estética do produto através da impressão visual que tem sobre ele; (e) a estética empírica, isto é, as ideias sobre os valores estéticos dos objetos destinados a determinado público.

Reportamo-nos também às dimensóes semióticas dos objetos (GOMES FILHO, 2000), que analisam a imagem simbólica do produto atrelada à estética do objeto, constituídas por propriedades e intençóes simbólicas intrínsecas, inerentes ou associadas ao objeto. Conectadas a determinadas características subjetivas dos alunos, as extensóes semióticas relacionam-se com os contextos socioculturais, quer dizer, aos modismos que surgem de tempos em tempos e que são reforçados pela ação da publicidade e propaganda sobre o produto - e muito apropriados às faixas etárias dos alunos dos ensinos fundamental e médio.

\section{Das extensóes plástico-visuais do objeto estético}

A formação estético-visual dos alunos são advindas, inevitavelmente, das citações artísticas e dos registros visuais, ambos considerados na perspectiva dos processos visuais da contemporaneidade. A narrativa imagética dos objetos deve estar relacionada à percepção da estética dos objetos no cotidiano do espaço escolar.

Pretende-se, a partir do desenvolvimento empírico do projeto, expandir os resultados em ampliaçóes plástico-visuais com base na sintaxe visual dos objetos estéticos, que se caracterizam por muitos aspectos, desde a impressão imediata da forma integrada ao conteúdo até mesmo de modo inverso.

A sintaxe visual aplicada ao objeto estético considera as temáticas e os estilos artístico-estéticos recorrentes da História da Arte; da mesma maneira em que a padronagem estilística, como a geometrização / o figurativismo / a abstração da forma; aos aspectos relacionados à estilização dos temas; à influência cromática; à interferência plástica das texturas e dos materiais utilizados; aos aspectos visuais ligados à profundidade; a inserção da palavra e/ou da (logo)marca; dentre outros.

A relevância do estudo da forma e do conteúdo nos objetos estéticos se deve justamente à hipótese de que esses parâmetros acerca das dimensóes estéticas e semióticas dos objetos não são comumente pormenorizados e expandidos pelos alunos-consumidores. O "gostar" ou não "gostar" de um objeto estético está, mesmo que inconscientemente, relacionado às especificidades visuais e contextualizaçóes histórico-culturais proeminentes nesses objetos, acentuadas com o consumo dos grupos escolares do CAp. Como propósito contundente da pesquisa, estende-se à formação da identidade estético-visual dos alunos, à valorização e ao reconhecimento de tais aspectos visuais, implícitos nos objetos estudados.

\section{Resultados alcançados em 2015 com os alunos do $7^{\circ}$ ano do ensino fundamental}

$\mathrm{Na}$ sequência, seguem alguns exemplos dos resultados visuais alcançados com o projeto de extensão no decorrer do ano letivo de 2015, a partir do estudo estético acerca de obras de arte à época do Concretismo no Brasil, o desenvolvimento plástico de novas padronagens geométricas em mochilas. E, mais adiante, os nomes próprios dos alunos como logomarcas figurativo-geométricas, com as técnicas de desenho e colagem, respectivamente. 
Torna-se importante mencionar que o movimento chamado Concretismo teve início como parte do movimento abstracionista moderno, com raízes em experiências como a do grupo De Stijl [O Estilo], criado em 1917, na Holanda, por Piet Mondrian (1872-1944), entre outros. O termo arte concreta é retomado por outros artistas, como Wassily Kandinsky (1866-1944), por exemplo, popularizando-se com Max Bill (19081994), ex-aluno da Bauhaus.

Os princípios do concretismo afastam da arte qualquer conotação lírica ou simbólica. O quadro, construído exclusivamente com elementos plásticos - planos e cores -, não tem outra significação senão ele próprio. A pintura concreta é "não abstrata", afirma Van Doesburg no manifesto do movimento. Max Bill é outro artista que também explora essa concepção de arte concreta, defendendo a incorporação de processos matemáticos à composição artística e a autonomia da arte em relação ao mundo natural. A obra de arte não representa a realidade, mas evidencia estruturas, planos e conjuntos relacionados, que falam por si mesmos. A arte concreta visa rediscutir a linguagem plástica moderna. Da pauta do grupo fazem parte também pesquisas sobre percepção visual, informadas pela teoria da Gestalt.

Bill é o principal responsável pela entrada desse ideário plástico na América Latina, sobretudo na Argentina e no Brasil, no período após a Segunda Guerra Mundial (19391945). A exposição do artista, em 1951, no Museu de Arte de São Paulo Assis Chateaubriand (Masp) e a presença da delegação suíça na $1^{\text {a }}$ Bienal Internacional de São Paulo, no mesmo ano, abrem as portas do país para as novas tendências construtivas, que são amplamente exploradas a partir de então. Os prêmios concedidos à escultura Unidade Tripartida de Max Bill, e à tela Formas, de Ivan Serpa (1923-1973) na 1a Bienal, realizada no Museu de Arte Moderna de São Paulo (MAM/SP), são sintomas da atenção despertada pelas novas linguagens pictóricas. $\mathrm{O}$ impacto das representaçóes estrangeiras na bienal se relaciona de perto às modificaçóes verificadas no meio social e cultural brasileiro. Cidades como Rio de Janeiro e São Paulo iniciam processos de metropolização, alimentados pelo surto industrial e pela pauta desenvolvimentista, que alteram a paisagem urbana. Do ângulo das artes visuais, a criação dos museus de arte e de galerias criam condiçóes para a experimentação concreta nos anos 1950, com o anúncio das novas tendências não figurativas.

$\mathrm{O}$ ano de 1952 e a exposiçáo do Grupo Ruptura marcam o início oficial do movimento concreto em São Paulo. Criado por Anatol Wladyslaw (1913-2004), Geraldo de Barros (1923-1998), Leopold Haar (1910-1954), Luiz Sacilotto (1924-2003), liderado pelo artista e crítico Waldemar Cordeiro (1925-1973), o grupo propóe, em seu manifesto, a "renovação dos valores essenciais das artes visuais", por meio das pesquisas geométricas, pela proximidade entre trabalho artístico e produção industrial, e pelo corte com certa tradição abstracionista anterior.

No Rio de Janeiro, alunos do curso de Ivan Serpa, no Museu de Arte Moderna do Rio de Janeiro (MAM/RJ), tendo como teóricos os críticos Mário Pedrosa (1900-1981) e Ferreira Gullar (1930), formam o Grupo Frente, em 1954. Fundado por Aluísio Carvão (1920-2001), Ivan Serpa (1923-1973), Lygia Clark (1920-1988), Lygia Pape (19272004), ao qual aderem em seguida Hélio Oiticica (1937-1980), Franz Weissmann (19112005), Abraham Palatnik (1928) e Rubem Ludolf (1932-2010), o grupo concreto carioca desenvolve a experimentação de todas as linguagens, ainda que no âmbito náo figurativo geométrico.

À investigação paulista centrada no conceito de pura visualidade da forma, o grupo carioca opóe uma articulação forte entre arte e vida - que afasta a consideração da obra 
como "máquina" ou "objeto" -, e maior ênfase na intuição como requisito fundamental do trabalho artístico. As divergências entre Rio e São Paulo se explicitam na Exposição Nacional de Arte Concreta, São Paulo, 1956, e Rio de Janeiro, 1957, início da ruptura neoconcreta, efetivada em 1959.

\section{Composiçóes geométricas com círculos}

Identificação do objeto estético: exemplo de mochila de aluno do ensino fundamental.

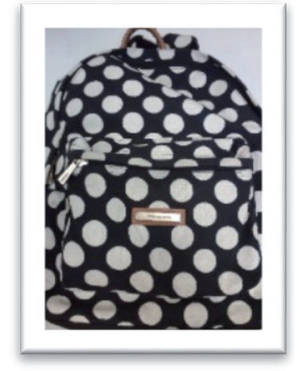

Influência artística: Obra de arte Concreção, 1980, Luiz Sacilotto.

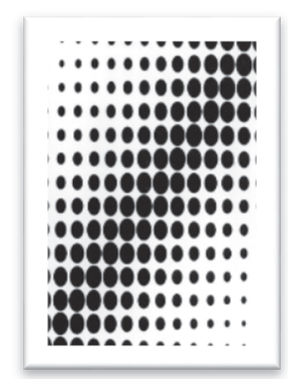

Luiz Sacilotto (SP, 1924 - SP, 2003)

As obras de Sacilotto tem influências do movimento da arte concreta. O artista explora o princípio de equivalência entre figura e fundo, a igualdade de medida entre cheios e vazios e as contraposiçóes entre positivo e negativo. Em suas composiçóes, as cores destacam ou suavizam a geometria; divide regularmente as figuras para multiplicálas, sem perder a referência inicial, e cria um jogo ambíguo com as formas, trabalhando com questóes que seráo desenvolvidas mais tarde pela $O p \mathrm{Art}^{1}$.

Estudo de padronagem geométrica: desenho de mochila.

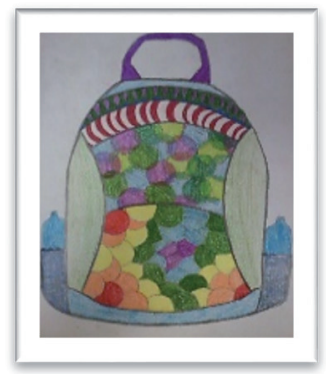

\section{Composiçóes geométricas com linhas retas horizontais e verticais}

Identificação do objeto estético: exemplo de mochila de Influência artística: Obra de arte Sem título, 1953, Ivan Serpa. aluno do ensino fundamental.
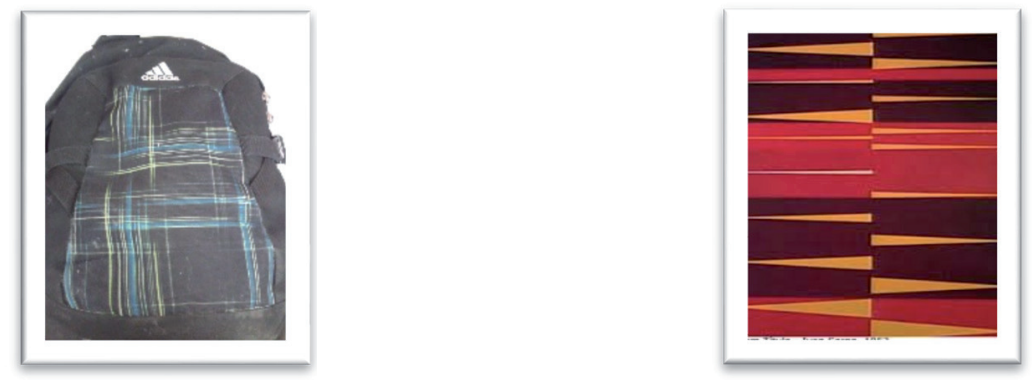

Ivan Serpa (RJ, $1923-$ RJ, 1973).

1 Disponível em: http://enciclopedia.itaucultural.org.br/pessoa10773/luiz-sacilotto. Acesso em: 29/10/2015 
$\mathrm{O}$ artista desenvolve trabalhos a partir da abstraçáo geométrica. $\mathrm{Na}$ década de 50, suas obras têm influência do Concretismo. Nas telas, desaparecem as referências ao mundo real, bem como a relaçáo harmoniosa entre figura e fundo. As obras têm formas geométricas e planas, organizadas matematicamente. Fundador do Grupo Frente com Abraham Palatnik e Franz Weissmann, nessa fase, suas obras apresentam formas geométricas e objetivas. $^{2}$

Estudo de padronagem geométrica: desenho de mochila.

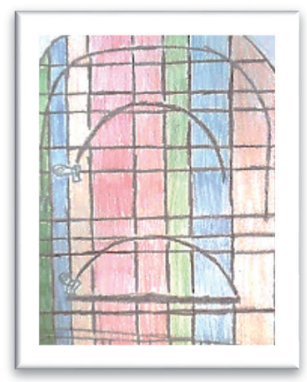

\section{Composiçóes geométricas com triângulos}

Identificação do objeto estético: exemplo de mochila de aluno do ensino fundamental.

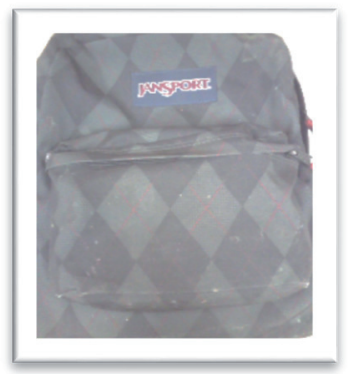

Influência artística: Obra de arte Sem título, 1970. Hércules Barsotti.

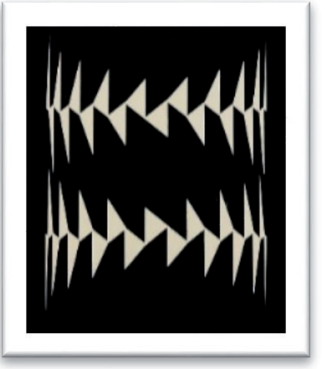

Hércules Barsotti (SP, 1914 - SP, 2010).

A partir da década de 50, o artista realiza desenhos voltados à abstração geométrica. Nesses trabalhos, divide a superfície em formas geométricas regulares, delineadas por linhas negras, de larguras e direçōes diferentes. A posição do traço, a distância e a justaposiçăo das formas criam a ilusão de deslocamento dos planos, sugerindo uma superfície tensa e quebradiça. Com Willys de Castro, atua como artista gráfico e se aproxima dos estudos da objetividade do Concretismo. ${ }^{3}$ 


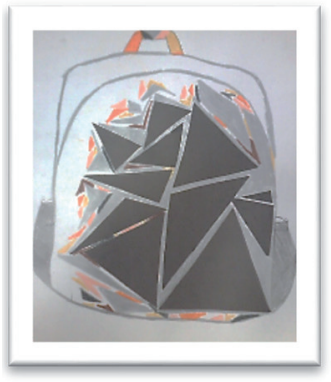

Os nomes próprios dos alunos como logomarcas figurativo-geométricas

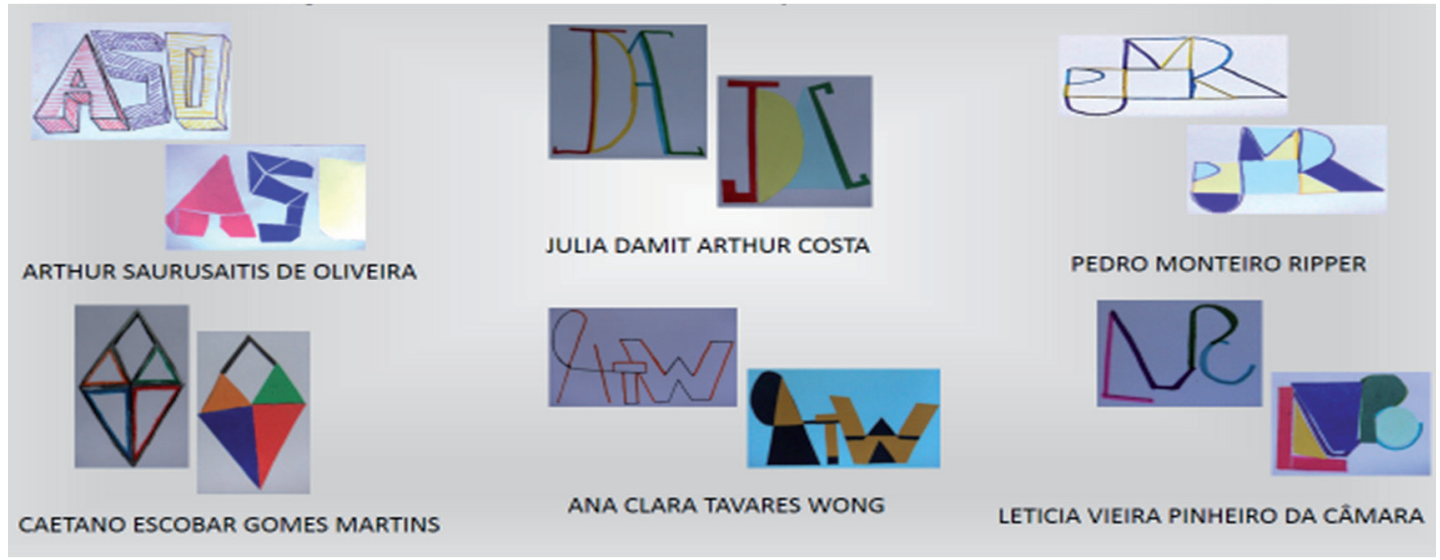

Composição com as letras iniciais dos nomes dos alunos. Desenho e colagem.

\section{Conclusóes}

$\mathrm{O}$ projeto de extensão $O C A p$-UERJ e suas impressóes visuais difunde a cultura visual através da prolixidade dos seus campos expressivos no campo das Artes Visuais, bem como a consequente massificação informacional. O projeto amplia a pesquisa sobre a identidade visual e suas influências estéticas na formaçáo continuada dos alunos dos ensinos fundamental e médio, no espaço escolar do CAp-UERJ.

Considerando-se que as turmas são heterogêneas, tanto as do ensino fundamental como as turmas do ensino médio, mescladas nos seus diferentes grupos sociais e culturais, a proximidade com o repertório visual e os objetos que os alunos usam no dia a dia do espaço escolar induz a problematizaçáo de um pensar/agir processual condizente com os estudos sobre o sistema de significaçóes visuais. Em outras palavras, a relaçáo que os alunos estabelecem com os objetos - seja por meio da sistemática de suas condutas coletivas ou de suas relaçôes culturais, o ainda, a partir das possibilidades subjetivas e autorais -, condiz com a "maneira de consumir" (Baudrillard, 1995) muito particular e conjugada com a dinamização da sociabilidade no espaço escolar.

Em grande parte, os grupos sociais na escola podem e devem ser identificados por meio do conjunto de objetos das mais diferentes naturezas que são ostentados, acumulados e/ou colecionados, inevitavelmente, por todos eles. "O grupo é o lugar simbólico onde se realiza [...] a complicada negociaçáo coletiva dos valores que giram em torno da construção das identidades singulares" (ROCHA, 2014, p. 28). Não raro, as atitudes e os posicionamentos dos alunos sáo caracterizados pela presença de objetos 
que dão visibilidade aos valores socioculturais e artístico-estéticos expressos pelo grupo. Vemos com o projeto como, de fato, a narrativa imagética está configurada (e estampada) através dos objetos, o que complementa de modo inevitável seus discursos (e identidades) visuais e culturais.

O desenvolvimento do estudo da historiografia da arte e demais especificidades epistemológicas pode tornar os alunos propensos à personalização e customização das suas identidades através desses bens de consumo - os objetos estéticos; identidades visuais, muitas vezes, aglutinadas nas suas opçôes e escolhas. Conhecer melhor as categorias e especificidades ligadas à produção estético-artística desses objetos pessoais; pesquisar o desenvolvimento alegórico da linguagem visual, assim como suas implicaçóes semióticas no imaginário cultural contemporâneo, tornam-se fundamentais para uma formação essencialmente valorativa e crítica dos sentidos artísticos que são suscitados por intermédio dos objetivos e das metodologias das linguagens artísticas e da História da Arte.

A insuficiência no mapeamento dos objetos artísticos mais utilizados pelos alunos no espaço escolar dificulta o registro - e o entendimento - da complexidade das demandas culturais e do "gosto" e "personificação" estéticos desses alunos (estudados enquanto indivíduos coletivos) em relação aos objetos quotidianos. As alusões alegóricas (tanto brasileiras como internacionais) no design dos objetos contextualizam os interstícios simbólicos que engendram o dinamismo visual e cultural no espaço escolar.

A identificação dos objetos estéticos de uso pessoal dos alunos do CAp-UERJ amplia o entendimento sobre o sistema de signos visuais que circulam na contemporaneidade, não somente no espaço do cotidiano escolar - o que nos leva a questionar se o aluno reconhece as referências estéticas dos objetos de uso pessoal que comumente utiliza. Entendemos como alusóes estéticas nos objetos não somente as atribuições ipsis litteris de obras de arte, mas as características artístico-estéticas desenvolvidas e difundidas enquanto alegorias no decorrer do alargamento da História da Arte. Desta forma, a permanente difusão dos referimentos culturais atribuídos aos objetos que circundam o cotidiano dos alunos justifica a relevância da pesquisa. A hibridizaçáo dos processos criativos das configuraçóes artísticas dos objetos estéticos logra outros espaços, sofrem deslocamentos. Inseridos em meio ao cotidiano massificado, assentam suas identidades a um constante questionamento pela legitimidade do objeto e sua alocação.

Consideramos, então, que as transformações entre a produção industrial e a produção artística, ampliando seus sentidos, coloca o objeto num lugar de designação artística. Transmutados de seus universos de origem, diferentes objetos passam a integrar o campo da arte e o valor utilitário do objeto passa a ter uma relação de equidade com sua forma, nesse caso sob a ótica da estetização. Sendo assim, acredita-se que não só a cultura visual reordena-se em consonância com um mercado diferenciado, como também o campo do Design incorpora em seus processos uma articulação estética e marcante entre a forma e a função.

Nesta pesquisa, Arte e Design são entendidos como áreas convergentes e interativas na perspectiva do ensino curricular de Artes Visuais e História da Arte no CAp-UERJ. A pretensão é de que possamos sistematizá-las e, mais importante, desenvolver a pesquisa acerca dos estudos contemporâneos sobre a cultura visual e demais questôes voltadas ao consumo de objetos pelos jovens, à medida que contribuem tanto com a concepçáo teórica acerca da identidade dos jovens como no que concerne às perspectivas estéticovisuais das narrativas imagéticas cariocas. 
Referências bibliográficas

ARGAN, G. Arte Moderna. São Paulo: Companhia das Letras, 1992.

ARNHEIM, R. Arte e percepção visual. São Paulo: Pioneira, 1980.

ASSOCIAÇÃO Objeto Brasil. Um olhar sobre o design brasileiro. São Paulo: SENAI, 2012.

BARBOSA, Ana Mae. Arte-Educação: conflitos/acertos. São Paulo: Max Limonad, 1984.

BARTHES, R. Sistema da moda. São Paulo: Edições 70, 1999.

BAUDRILLARD, J. A sociedade de consumo. Lisboa: Edições 70, 1981.

O sistema dos objetos. São Paulo: Perspectiva, 1993.

BENJAMIN, W. A obra de arte na era de sua reprodutibilidade técnica. In:

Magia e técnica, arte e política: ensaios sobre literatura e história da cultura. São Paulo: Brasiliense, Obras escolhidas, v.1, 1985 e 2008.

BORDIEU, P. O poder simbólico. Rio de Janeiro: Bertrand Brasil, 1989.

A economia das trocas simbólicas. São Paulo: Perspectiva, 2003.

BRITO, R. Neoconcretismo: vértice e ruptura do projeto construtivo brasileiro. São Paulo: Cosac \& Naify Edições, 1999.

CEIA, C. e-Dicionário de termos literários. 2010. Disponível em: http://edtl.fcsh.unl. pt/. Acesso em: 10 dez. 2015.

CHIPP, H. B. Teorias da Arte Moderna. São Paulo: Martins Fontes, 1993.

DIDI-HUBERMAN, G. 0 que vemos, o que nos olha. São Paulo: Ed. 34, 1998.

DONDIS, A. D. Sintaxe da linguagem visual. São Paulo: Martins Fontes, 2007.

FABBRINI, R. A arte depois das vanguardas. Campinas: UNICAMP, 2002.

FERREIRA, A. B. H. Dicionário Aurélio de Língua Portuguesa. São Paulo: Positivo, 2010.

GOMBRICH, E. H. A História da Arte. São Paulo: Livros Técnicos e Científicos Editora, 1999.

GOMES FILHO, J. Design do objeto - bases conceituais. São Paulo: Escrituras, 1995. 
Escrituras, 2000.

Gestalt do objeto - sistema de leitura visual da forma. São Paulo,

HERNÁNDEZ, F. Cultura visual, mudança educativa e projeto de trabalho. Porto Alegre: Artmed, 2000.

. Catadores da cultura visual: proposta para uma nova narrativa educacional.

Porto Alegre: Mediação, 2007.

HONNEF, K. Pop Art. Alemanha: Taschen, 2004.

MORRIS, W. C. Fundamentos da teoria dos signos. Barcelona: Paidós, 1985.

PAREYSON, L. Os problemas da estética. São Paulo: Martins Fontes, 1989.

PEIRCE, C. S. Semiótica. São Paulo: Perspectiva, 2003.

PLAZA, J. Tradução Intersemiótica. São Paulo: Perspectiva, 2003. 
PONTUAL, R. Entre dois séculos: arte brasileira do século XX na Coleção Gilberto Chateaubriand. São Paulo: Editora JB, 1987.

ROCHA, E.; PEREIRA, C.; BARROS, C. (Orgs.). Juventude e consumo. Rio de Janeiro, Mauad, 2009. Cultura e experiência midiática. Rio de Janeiro: Ed. PUC-Rio: Mauad, 2014.

STANGOS, N. Conceitos da Arte Moderna. Rio de Janeiro: Zahar, 2000.E 